\title{
CALIDAD BACTERIOLOGICA DE ENSALADAS DE ZANAHORIA RALLADA Y EFICACIA DE TRATAMIENTOS PREVIOS A SU CONSUMO
}

\author{
Gentili Alejandro Raúl ${ }^{1}$ Marzocca María Alejandra' ${ }^{1}$ Oriani Alejandra Soledad ${ }^{1}$ Baldini Mónica Diana ${ }^{1}$
}

\author{
Departamento de Biología, Bioquímica y Farmacia de la Universidad Nacional del Sur
}

\section{RESUMEN}

Introducción: La venta de ensaladas listas para consumir creció en los últimos años. Desde 2012, el Código Alimentario Argentino (CAA), Art. 925 quater, regula la aptitud de las mismas. Objetivo: Evaluar la calidad bacteriológica de ensaladas de zanahoria rallada y estudiar la reducción bacteriana frente al lavado con agua potable y la desinfección con hipoclorito de sodio y con una solución de vinagre. Métodos: Se analizaron 30 muestras de ensalada de zanahoria rallada y se les aplicaron los tratamientos mencionados, para evaluar las diferencias se realizó una prueba no paramétrica de Friedman. Resultados: El 50\% de las muestras no cumplió con el CAA para Escherichia coli. El porcentaje disminuyó al 45 con un lavado previo o tratamiento con vinagre. Entre estos tratamientos no hubo diferencias. La desinfección con hipoclorito aumentó la aptitud un $15 \%$ y presentó diferencias altamente significativas con el resto $(p<0.01)$. Salmonella se encontró en el $7 \%$ de las muestras y se eliminó con hipoclorito. E.coli 0157 no se detectó. El $100 \%$ de las muestras presentaron recuentos de Staphylococcus aureus menores a 2500 UFC. $\mathrm{g}^{-1}$, lo cual no constituiría un riesgo potencial. Discusión: Se destaca la importancia de la calidad microbiológica de la materia prima, dado que el $35 \%$ de las muestras no logró la aptitud aun aplicando el tratamiento con hipoclorito. Se plantea la necesidad del rotulado apropiado para evitar dejar librado al criterio del consumidor el manejo del alimento. La implementación de Buenas Prácticas Agrícolas y de Manufactura contribuiría a obtener alimentos inocuos, de mejor calidad microbiológica.

Palabras Clave: vegetales mínimamente procesados; calidad bacteriológica; seguridad alimentaria.

\section{ABSTRACT}

Introduction: The sale of ready-to-eat salads increased in recent years. Since 2012, the Código Alimentario Argentino (CAA), Art. 925 quater, regulates its microbiological quality. Objective: To evaluate the bacteriological quality of grated carrot and to study the reduction of bacterial counts applying washing with tap water, disinfection with sodium hypochlorite and with a vinegar solution. Methods: Thirty grated carrot samples were analyzed and the above-mentioned treatments were applied. A nonparametric Friedman test was performed to evaluate the differences. Results: $50 \%$ of the samples expended did not achieve the requirements of the CAA for Escherichia coli. The percentage dropped to 45 with a previouswash or treatment with vinegar. No differences were found between these treatments. When disinfection with hypochlorite was done $15 \%$ more reached the requirements and this treatment showed highly significant differences with the rest $(p<$ $0,01)$. Salmonella was found in $7 \%$ of the samples and were eliminated with hypochlorite. E.coli 0157 was not detected. $100 \%$ of the samples showed Staphylococcus aureus counts less than 2500 UFC.g-1, which do not constitute a potential risk. Discussion: It should be pointed out the importance of the microbiological quality of raw material, since the $35 \%$ of the samples do not reach the requirements even applying the treatment with hypochlorite. Appropriate labeling is necessary to avoid leaving up to consumers criteria the food handling. The implementation of Good Agricultural Practices and Manufacturing would contribute to safe food, and of better microbiological quality.

Key words: minimally processed vegetables; bacteriological quality; food Safety

Citation: Gentili AR. Marzocca MA. Oriani AS. Baldini M. (2017) Calidad bacteriológica de ensaladas de zanahoria rallada y eficacia de tratamientos previos a su consumo. Revista de Salud Pública y Nutrición, 16(1), 9-15

Editor: Esteban G. Ramos Peña, Dr. CS., Universidad Autónoma de Nuevo león, Facultad de Salud Pública, Monterrey Nuevo León, México Copyright: @2017 Gentili AR et al. This is an open-access article distributed under the terms of Creative Commons Attribution License [CC BY-ND 4.0], which permits unrestricted use, distribution, and reproduction in any medium, provided the original author and source are credited. Competing interests: The authors have declared that no competing interests exist.

DOI: https://doi.org/10.29105/respyn16.1-2

Email: agentili@uns.edu.ar 


\section{Introducción}

Las enfermedades transmitidas por los alimentos representan uno de los problemas de salud pública más importantes, con repercusiones que inciden en el ámbito económico, social y político. La contaminación de los alimentos es en muchos casos, el resultado de problemas ambientales más generales (ausencia de buenas prácticas de manufactura, falta de infraestructura sanitaria y de higiene adecuadas) que se traducen en altos riesgos para los consumidores.

Las frutas y verduras son parte importante de una dieta saludable por lo cual la venta de ensaladas listas para su consumo ha crecido exponencialmente en los últimos años (Tabán y Halkman, 2011; Castro-Rosas et al. 2012; Olaimat y Holley, 2012). En consecuencia, en la mayoría de las verdulerías locales comenzaron a venderlas envasadas, sin ningún tipo de rotulación, dejando a criterio del consumidor si éstas deberían ser lavadas y/ o desinfectadas o no, previo al consumo.

Los alimentos de origen vegetal pueden vehiculizar microorganismos patógenos y causar enfermedades (Castro-Rosas et al., 2012; Lynch et al., 2009). La contaminación de las verduras y hortalizas crudas puede provenir del empleo de sistemas de riego (García et al, 2015), de la tierra, de la fertilización, de la materia fecal de animales y humanos y de las prácticas aplicadas durante su recolección, transporte, distribución, almacenamiento y manipulación (Franz et al, 2010).

La mayoría de las veces, las ensaladas crudas son consumidas sin ningún tratamiento de lavado y/o desinfección adecuado adicional que elimine a las potenciales bacterias patógenas. A partir del año 2012 el Código Alimentario Argentino (C.A.A), en su art. 925 quater, regula la aptitud de las mismas mediante el cumplimiento de ciertos criterios microbiológicos.

Como consecuencia de las nuevas tendencias alimentarias, se ha elevado la frecuencia de gastroenteritis asociadas (Doyle y Erickson, 2008; Yaron y Römling, 2014). Salmonella spp. es el microorganismo con mayor incidencia en la producción de brotes relacionados al consumo de vegetales crudos, es responsable del $30,5 \%$ de todos los casos y se está incrementando en los últimos años
(EFSA, 2012). En Estados Unidos, Grant y colaboradores (2008) detectaron Escherichia coli enterohemorrágica O157: H7 en espinacas. Esta misma bacteria fue hallada por Rubeglio y Tesone (2007) en cebollas de verdeo y muestras de verduras cortadas y preparadas en bandejas para su venta, en un trabajo que incluía distintos tipos de muestras provenientes de la Capital Federal y Gran Buenos Aires (Argentina).

La tecnología de procesamiento mínimo de productos frutihortícolas se encuentra en auge, pero durante el pelado y trozado se aumenta la superficie de tejido haciéndolo más susceptible a las alteraciones microbianas; además se incrementa la tasa respiratoria, la producción de etileno y el metabolismo de los compuestos fenólicos que aceleran la senescencia y el deterioro de los productos frutíhortícolas (Ramos et al, 2013).

Lo antedicho pone en evidencia que el consumo de vegetales mínimamente procesados (VMP) puede representar un riesgo para la salud pública y señala la necesidad de conocer las realidades de las distintas regiones del país en cuanto a su venta y consumo.

Los objetivos que se plantearon en el presente trabajo fueron: a) Evaluar la calidad bacteriológica de los VMP, expendidos en verdulerías, supermercados y rotiserías de la ciudad de Bahía Blanca (Provincia de Buenos Aires, Argentina) a fin de conocer el grado de cumplimiento con lo establecido por el C.A.A. en su artículo 925 quater categoría 2, b) Estudiar la reducción de los recuentos bacterianos cuando se aplican distintos tratamientos.

\section{Material y Métodos}

En primera instancia, para la elección del tipo de vegetales a estudiar y para conocer los tratamientos a que son sometidos los mismos previo a su consumo se realizó una encuesta cerrada on line que se envió a 250 personas de la ciudad de Bahía Blanca, tomadas al azar de una base de datos. Se realizaron ocho preguntas, cinco tendientes a recabar información sobre el uso de VMP:

\section{1. ¿Consume vegetales mínimamente procesados?}


2. ¿Qué tipo de producto consume más frecuentemente?

3. ¿Qué tratamiento previo al consumo realiza?

4. En caso de realizar desinfección de los vegetales ¿Qué utiliza?

5. ¿A quién destina los vegetales mínimamente procesados?

Las tres preguntas restantes indagaban sobre las características de los participantes (edad, sexo y ocupación).

A partir de los resultados de la encuesta se decidió trabajar con ensaladas de zanahoria rallada y evaluar la eficacia de los tres tratamientos más utilizados por los consumidores: lavado con agua potable, desinfección con hipoclorito de sodio y con una solución de vinagre.

\subsection{Recolección de muestras:}

Se analizaron 30 muestras de ensalada de zanahoria rallada, adquiridas en comercios distribuidos aleatoriamente en el macrocentro de la ciudad de Bahía Blanca. Cada establecimiento se muestreó al menos en dos oportunidades a lo largo de un año. Las muestras se trasladaron al laboratorio en forma inmediata, conservando la cadena de frío. El tiempo transcurrido entre la obtención de las muestras y la realización de los ensayos no superó las 2 h. En el momento de obtención de las muestras se verificó si el producto se mantenía refrigerado.

Asimismo se registraron las características del envase y la existencia de rótulos donde se especificara la fecha de caducidad y si el producto se encontraba listo para ser consumido o si necesitaba algún tratamiento previo como lavado y/o desinfección.

\subsection{Análisis bacteriológicos:}

Los análisis bacteriológicos se realizaron de acuerdo a lo exigido por el artículo 925 quater del C.A.A, en el que se diferencian tres categorías. En el presente trabajo se consideraron las exigencias establecidas para la categoría 2, vegetales mínimamente procesados: hortalizas y frutas frescas, enteras $\mathrm{o}$ cortadas, peladas o no, lavadas, tratadas (desinfectadas) o no, y envasadas, listas para consumir. Se adoptó esta decisión teniendo en cuenta que la mayoría de los consumidores adquieren los
VMP suponiendo que no requieren ningún tratamiento previo a su ingesta.

Se pesaron asépticamente $25 \mathrm{~g}$ de la muestra, se colocaron en agua peptonada $(0,1 \%, \mathrm{pH} 7,0 \pm 0,2) \mathrm{y}$ se homogeneizaron, a fin de liberar las bacterias. Se realizó la búsqueda de Escherichia coli genérica, Staphylococcus aureus, y Escherichia coli O157. Para la investigación de Salmonella spp se efectuó la dilución en caldo Lactosado (Merck).

La investigación de E. coli se realizó por la técnica de Número Más Probable (NMP) en caldo Lauril Sulfato (Britania) (prueba presuntiva) para recuperar las células estresadas. Los tubos se incubaron a $35^{\circ}$ $\pm 0.5 \mathrm{C}$ durante 24 a 48 horas. Los tubos positivos se resembraron en el medio selectivo confirmatorio caldo Bilis Lactosa Verde Brillante (Merck). Los tubos se incubaron a $35 \pm 0.5{ }^{\circ} \mathrm{C}$ durante 24 a 48 horas. Los positivos se repicaron a tubos con caldo EC (Merck) y se incubaron a $45 \pm 0.5{ }^{\circ} \mathrm{C}$. Los resultados se expresaron como NMP.g-1. Los tubos positivos se aislaron en agar EMB (Merck) y las colonias típicas se identificaron bioquímicamente (Feng et al, 2013).

Para la búsqueda de Salmonella spp. a partir de la siembra en caldo Lactosado $\left(24 \mathrm{~h}\right.$ a $\left.37^{\circ} \mathrm{C}\right)$ se realizó un enriquecimiento selectivo en los medios Rappaport-Vassiliadis (preparado a partir de sus ingredientes) y en caldo Tetrationato (Merck, $24 \mathrm{~h}$ a $37^{\circ} \mathrm{C}$ ). Posteriormente alícuotas de los mismos se sometieron al método de inmunocromatografía RapidChek® Salmonella (Romer Labs). Los casos positivos se confirmaron sembrando simultáneamente en Agar Sulfito-Bismuto (Merck), Agar Hecktoen (Merck) y Agar Xylosa lysina desoxycolato (XLD, Merck) (Andrews et al, 2016). Se confirmó el género bioquímicamente (Mac Faddin, 2003)

Para la investigación presuntiva de E. coli O157, 25 $\mathrm{g}$ de la muestra se resuspendieron en $225 \mathrm{ml}$ de caldo EC modificado con novobiocina (Merck), se incubó a $42^{\circ} \mathrm{C}$ durante $24 \mathrm{~h}$ y finalmente una alícuota se evaluó por el método RapidChek® E.coli O157 (Romer Labs) (BAM, FDA, 2001).

La sensibilidad de ambos métodos inmunocromatográficos, según los fabricantes de los kits, es de 1 bacteria en $25 \mathrm{~g}$ de muestra analizada. 
Si bien el estudio de Staphyloccus aureus no está considerado dentro del artículo 925 quater del C.A.A. para VMP, se incluyó su búsqueda y cuantificación en las muestras sin tratamiento, con el fin de evaluar la aplicación de Buenas Prácticas de Manufactura durante el procesamiento de los vegetales. Para ello se utilizó la técnica de recuento en placa en agar Baird Parker (Merck) y posterior tipificación bioquímica (ISO 6888-1, 1999).

2.3 Evaluación de los procesos de lavado y desinfección Cada una de las muestras de ensalada de zanahoria rallada adquiridas en el mercado local se dividió en cuatro fracciones a las que se aplicó un tratamiento distinto seleccionado de acuerdo a los resultados obtenidos en la encuesta:

1. muestra sin tratar

2. muestra lavada por cinco minutos con agua potable $(0,3 \mathrm{mg} . \mathrm{L}-1$ cloro libre)

3. muestra desinfectada con hipoclorito de sodio $(100 \mathrm{ppm} \mathrm{v/v)} \mathrm{pH}<8$. El tiempo de contacto fue $5 \mathrm{~min}$ a temperatura ambiente.

4. muestra tratada con solución de vinagre (acidez: $5 \mathrm{~g} \%$ de ácido acético) a una concentración de $50 \mathrm{ppm}(\mathrm{v} / \mathrm{v})$. El tiempo de contacto fue $5 \mathrm{~min}$ a temperatura ambiente.

\subsubsection{Efecto del lavado:}

Los vegetales se lavaron bajo chorro de agua potable en un tamiz simulando las condiciones del tratamiento realizado a nivel doméstico. Posteriormente se eliminó el exceso de agua, agitando sobre el tamiz durante aproximadamente 30 segundos y se sembró como se explicó en Análisis bacteriológicos (ítem 2.2). En cada caso se determinó la concentración de cloro libre en el agua de lavado, con un kit Hach CN 66.

\subsubsection{Efecto de la desinfección:}

Otra fracción de las muestras se sumergió durante 5 min en una solución desinfectante de hipoclorito de sodio $100 \mathrm{ppm}$, preparado en el momento con agua potable. Transcurrido el tiempo de acción del desinfectante, se enjuagó y escurrió como se describió en Efecto del lavado (ítem 2.3.1).

Idéntico procedimiento se llevó a cabo con una solución de vinagre (50 ppm), con pH 4.
Para evaluar las diferencias entre los tratamientos se realizó una prueba no paramétrica de Friedman (Conover, 1999).

\section{Resultados}

De la encuesta participaron 200 personas (62\% mujeres), el $92 \%$ de los encuestados con edades entre 18 y 60 años. El sondeo puso en evidencia que el 94 $\%$ de los participantes consumía VMP (el $33 \%$ diariamente, el $24 \%$ semanalmente y el $37 \%$ esporádicamente). El $31 \%$ de los encuestados adquirió en las verdulerías mix de vegetales para cocinar, el $25 \%$ ensaladas de zanahoria rallada, el 13 $\%$ remolacha y huevo duro y el $6 \%$ restante repollo y zanahoria ralladas. La totalidad de los encuestados destinó los VMP para consumo personal y familiar.

En la figura 1 se presentan los resultados del manejo de los alimentos previo al consumo, que refirieron hacer los encuestados.

Figura 1. Resultados de la encuesta realizada para el manejo de las ensaladas de zanahoria rallada previo a su consumo.

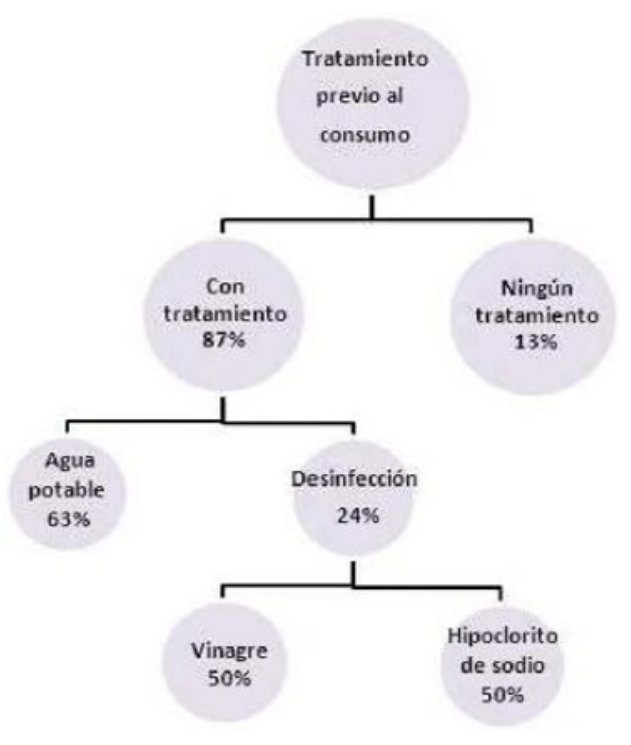


En la tabla 1 se muestran los porcentajes de muestras de ensalada de zanahoria rallada, adquiridas en la ciudad de Bahía Blanca, que cumplen con el CAA, así como la eficiencia de los distintos tratamientos aplicados. Salmonella spp. se detectó en dos muestras (7\%) y se eliminó en el tratamiento con hipoclorito. E. coli $\mathrm{O} 157$ no se evidenció en ninguna de las muestras. No se encontraron diferencias entre los tratamientos de lavado con agua potable y con la solución de vinagre.

Tabla 1 Porcentaje de cumplimiento de las exigencias microbiológicas del Artículo 925 quater categoría 2 del Código Alimentario Argentino, de las ensaladas de zanahoria rallada, en relación a los tratamientos aplicados.

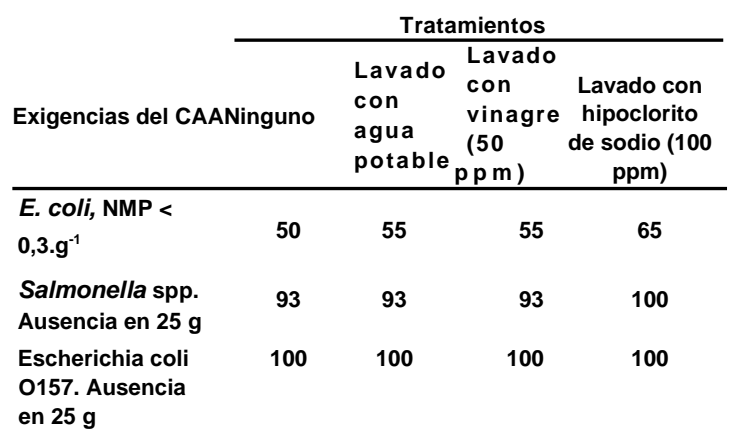

Fuente: Elaboración propia

CAA: Código Alimentario Argentin

$\mathrm{n}=30$

En cuanto a S. aureus, el $67 \%$ de las muestras presentaron recuentos menores a 50 Unidades Formadoras de Colonias por gramo (UFC. $g^{-1}$ ), el

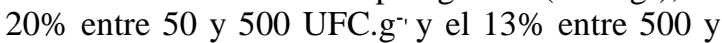
2500 UFC.g $^{-}$.

Sobre las muestras que inicialmente no cumplieron con los criterios de aceptación del C.A.A. se realizó la prueba no paramétrica de Friedman, considerando los recuentos iniciales de la bacteria indicadora y las reducciones de los mismos luego de aplicar los diferentes procedimientos. Ésta detectó diferencias altamente significativas entre el tratamiento con hipoclorito y el resto $(\mathrm{p}<0,01)$. La concentración de ácido orgánico utilizada no mostró actividad antibacteriana, a pesar de la creencia popularmente instalada. El lavado con solución de hipoclorito aumentó en un $15 \%$ las muestras aptas para consumo.
La totalidad de los VMP adquiridos se exhibieron refrigerados, en bandejas de policloruro de vinilo y envueltos en film de polipropileno. El rotulado solo estuvo presente en dos muestras provenientes de supermercados, no así en las de verdulerías ni rotiserías. Por lo cual, en la mayoría de los casos, tampoco constaba la fecha de elaboración y caducidad.

\section{Discusión}

Se puso en evidencia que solo el $50 \%$ de las muestras de VMP analizadas cumplió con las exigencias del C.A.A. para $E$. coli, porcentaje que se elevó al $55 \%$ cuando se las lavó previamente o cuando se las trató con vinagre.

El lavado con hipoclorito aumentó a un $65 \%$ la cantidad de muestras aptas. Esto demuestra la importancia de la calidad de la materia prima ya que aún con este tratamiento no siempre se logra la aptitud del producto. La implementación de Buenas Prácticas Agrícolas y Buenas Prácticas de Manufactura contribuiría a ofrecer a los consumidores alimentos inocuos y de mejor calidad microbiológica.

En cuanto a la presencia de Staphylococcus aureus, se debe tener en cuenta que la dosis de toxina necesaria para provocar los síntomas $(1-5 \mu \mathrm{g} / \mathrm{g}$ de alimento) se alcanza cuando la población de esta bacteria excede los $1.10^{5}$ bacterias por $g$ (Jablonski y Bohach, 2001), por lo tanto los valores encontrados en el presente estudio no constituirían un riesgo potencial de intoxicaciones alimentarias siempre y cuando las condiciones de almacenamiento fueran las adecuadas para impedir su proliferación.

La ausencia de rótulos en el $93 \%$ de las muestras, dejó librado al criterio del comprador el manejo del alimento previo a su consumo, con los riesgos que esto conlleva. Cabe destacar que en el $7 \%$ de las muestras sin tratamiento se detectó salmonelas y que solo el $12 \%$ de los encuestados realizó un tratamiento apropiado para eliminarla.

\section{Conclusiones}

Si bien el presente es un estudio exploratorio se ponen en evidencia falencias en el cumplimiento de las exigencias del C.A.A. en su art. 925 quater 
categoría 2 con respecto a las ensaladas de zanahoria rallada que se venden en la ciudad. Esta situación, que mejoraría si al comprador se le advirtiera mediante un rótulo claro la necesidad de lavar y/o desinfectar los VMP, pone de manifiesto la falta de control apropiado.

El reto es generar la información adecuada al alcance del público basada en criterios objetivos y claros con la finalidad de dar sustento al cuidado, manejo y consumo de VMP, enfatizando la importancia de un control sanitario estricto y constante sobre ellos.

Para producir alimentos de bajo riesgo es esencial obtener datos veraces y actualizados que contribuyan a paliar el vacío de conocimiento que existe sobre la comercialización de estos productos en nuestra región, permitiendo así desarrollar programas destinados a eliminar peligros microbianos asociados al consumo.

Queda claro que para conseguir el objetivo de seguridad alimentaria, se requiere un ejercicio de responsabilidad compartida entre todos los actores involucrados en la cadena alimentaria, empezando por los productores, pasando por los manipuladores y distribuidores y acabando en los consumidores.

\section{Agradecimientos:}

el presente trabajo fue realizado en el marco de un Proyecto General de Investigación financiado por la Secretaría de Ciencia y Tecnología de la Universidad Nacional del Sur de Bahía Blanca. Argentina.

\section{Bibliografía}

Andrews W, Wang H, Jacobson A, Hammack, T Cap. 5 Salmonella Bacteriological Analytical Manual (BAM), FDA 2016, consultado 08/11/2016, disponible en:

http://www.fda.gov/Food/FoodScienceResearch/Laborato ryMethods/ucm2006949.htm

Bacteriological Analytical Manual (BAM) FDA. Appendix 1 Rapid Methods for Detecting Foodborne Pathogens Version: January 2001 Pages 1 - 14,

consultado el 08/11/2016, disponible en: http://www.epa.gov/sites/production/files/201507/documents/fda-bam-appendix1.pdf .

Castro-Rosas J, Cerna-Cortés JF, Méndez-Reyes E ,LopezHernandez D, Gómez-Aldapa CA ,Estrada-Garcia T.
Presence of faecal coliforms, Escherichia coli and diarrheagenic E. coli pathotypes in ready-to-eat salads, from an area where crops are irrigated with untreated sewage wáter. Int J Food Microbiol. 2012; 156: 176180.

Código Alimentario Argentino, Ley 18284, 18/07/69. Decreto Reglamentario 2126/71, 30/06/1971. Actualizado 06/2013, consultado el 08/08/2016,

disponible

en: http://www.anmat.gov.ar/alimentos/codigoa/Capitulo XI.pdf

Conover W J. Practical Nonparametric Statistics. 3rd edition., J Wiley \& Sons, New York, 1999, 592 pages.

Doyle M, Erickson M. Summer meeting 2007-the problems with fresh produce: an overview. J Appl Microbiol. 2008; 105: 317-30.

EFSA (Autoridad Europea de Seguridad Alimentaria). The European Union summary report on trends and sources of zoonoses, zoonotic agents and foodborne outbreaks in 2010. The EFSA Journal 2012;10: 2594-99.

Feng P, Weagant S, Grant M, Burkhardt W. Cap. 4 Enumeration of Escherichia coli and the Coliform Bacteria Bacteriological Analytical Manual (BAM) FDA 2013, consultado el 08/11/2016, disponible en:

http://www.fda.gov/Food/FoodScienceResearch/Laborato ryMethods/uc2006949.htm

Franz E, Tromp SO, Rijgersberg, Van Der Fels-Klerx HJ. Quantitative microbial risk assessment for Escherichia coli O157:H7, Salmonella, and Listeria monocytogenes in leafy green vegetables consumed at salad bars. J Food Protec.2010;73: 274-85.

García BC, Dimasupil MA, Vital PG, Widmer KW, Rivera WL. Fecal contamination in irrigation water and microbial quality of vegetable primary production in urban farms of Metro Manila, Philippines. J Environ Sci Health B. 2015;50:734-43.

Grant J, Wendelboe AM, Wendel A, Jepson B, Torres P, Smelser C, Rolfs RT. Spinach-associated Escherichia coli O157:H7 Outbreak, Utah and New Mexico, Emerg Infect Dis. 2008; 14:1633-36.

ISO 6888-1: Microbiology of food and animal feeding stuffs -- Horizontal method for the enumeration of coagulase-positive staphylococci (Staphylococcus aureus and other species) 1999.

Jablonski LM, Bohach GA. Staphylococcus aureus. En: Doyle MP, Beuchat LR, Montville TJ, editors. Food Microbiology: Fundamentals and Frontiers. 2nd edition. Washington DC, ASM Press, 2001, 411-34. 
Lynch. MF, Tauxe RV, Hedberg CW. The growing burden of foodborne outbreaks due to contaminated fresh produce: risks and opportunities. Epidemiol Infect, 2009; 137: 307-15.

MacFaddin JF. Pruebas Bioquímicas para la identificación de bacterias de importancia clínica, 3era Edición. Madrid España, Ed. Médica Panamericana, 2003, pp 850 .

Olaimat A.N, Holley RA. Factors influencing the microbial safety of fresh produce: a review. Food Microbiol. 2012; 32:1-19.

Ramos B, Miller F, Brandão T, Teixeira P, Silva C. Fresh fruits and vegetables-An overview on applied methodologies to improve its quality and safety. Innovative Food Science and Emerging Technologies. 2013; 20: 1-15.

Rubeglio EA, Tesone S. Escherichia coli O157 H7: presencia en alimentos no cárnicos. Arch Argent Pediatr. 2007;105:193-4.

Taban BM, Halkman. Do leafy green vegetables and their ready-to-eat [RTE] salads carry a risk of foodborne pathogens? Anaerobe. 2011; 17: 286-87.

Yaron S, Römling U. Biofilm formation by enteric pathogens and its role in plant colonization and persistence .Microbial Biotech. 2014; 7:496-516. 